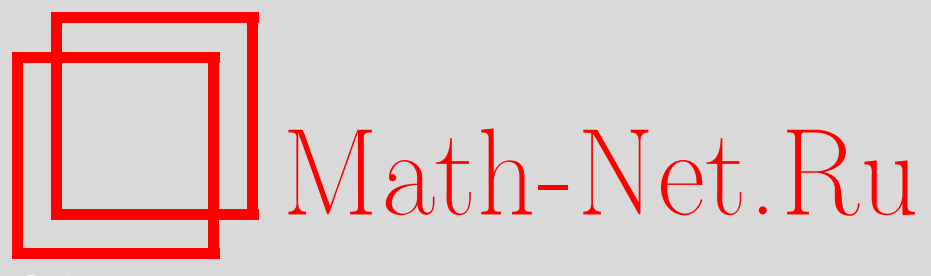

К. Е. Вейн, П. Жерард, В. Крейг, С. Б. Куксин, А. Г. Сергеев, А. В. Фурсиков, Конференция по математической гидродинамике, УМH, 2007, том 62, выпуск $3,3-4$

DOI: https://doi.org/10.4213/rm7147

Использование Общероссийского математического портала Math-Net.Ru подразумевает, что вы прочитали и согласны с пользовательским соглашением http://www . mathnet.ru/rus/agreement

Параметры загрузки:

IP : 54.166 .219 .16

26 апреля 2023 г., $17: 14: 41$

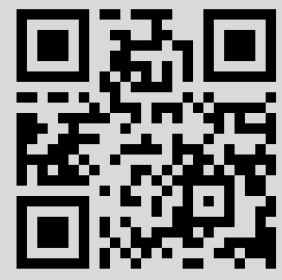




\section{Конференция по математической гидродинамике}

Тематикой этого специального выпуска Успехов математических наук являются математические аспекты гидродинамики, ставшие предметом докладов на недавней Конференции по математической гидродинамике. Конференция проходила в Математическом институте им. В. А. Стеклова в течение недели 12-17 июня 2006 г. Динамика жидкости на протяжении многих лет является источником важных и трудных математических задач, относящихся, в частности, к теории дифференциальных уравнений с частными производными и динамическим системам. В качестве выдающихся примеров применения аналитических методов к теории дифференциальных уравнений гидродинамики можно отметить работы Т. Леви-Чивиты (1925) о поверхностных водяных волнах, Ж. Лерэ (1934) и Э. Хопфа (1941) об уравнениях Навье-Стокса или К.-О. Фридрихса (1954) о теории плоских волн и об ударной взрывной волне. Непосредственной целью соответствующих исследований является построение строгого математического фундамента гидродинамики в попытке ответить на такие основополагающие вопросы, как наличие особенностей у решений; существование, непрерывность и единственность потока, понимаемые в том или ином смысле; возможные асимптотические поведения решений на больших временах, а также обнаружение и изучение структур, инвариантных относительно потока. Научная причина подобного пристального интереса состоит в том, что гидродинамика является основой успешного развития физики и технических дисциплин, которые, в свою очередь, привносят множество научных достижений, влияющих на современное общество. На протяжении ряда последних десятилетий математический интерес к динамике жидкости был чрезвычайно велик, и разработанные подходы к ее задачам служат достижениям в вычислительных методах, математическом моделировании и многих других областях, представляющих большой научно-технический интерес. Тематикой прошедшей в Математическом институте им. В.А. Стеклова конференции стали исследования уравнений Эйлера и уравнений Навье-Стокса динамики жидкости, как сжимаемой, так и несжимаемой, а также уравнений динамики волн свободных поверхностей. В последние годы достигнут прогресс в целом ряде фундаментальных и сложных проблем этой области. Целью конференции было изложить текущее состояние вопроса разнородному математическому сообществу исследователей по этой тематике и обсудить перспективы дальнейшего развития этой области.

Содержанием настоящего выпуска являются статьи участников конференции. Он включает материалы по уравнениям Эйлера, в том числе:

(i) изложение нынешнего математического знания о решениях уравнений Эйлера и о возможной взаимосвязи неустойчивости с турбулентностью (Бардос и Тити),

(ii) дискуссию об аксиально-симметричных несжимаемых потоках с ограниченным вихрем (Даншен),

(iii) подход к уравнению Эйлера на основе теории кватернионов (Гиббон). 
Также приводятся

(iv) обзор математических результатов для уравнений поверхностных волн на воде (Крейг и Вейн)

и ряд обзоров по уравнениям Навье-Стокса для несжимаемой жидкости, в том числе:

(v) достижения в теории локальной регулярности (Серегин),

(vi) дискуссии о современном состоянии теории уравнений Навье-Стокса для сжимаемой жидкости (Файрайзл, а также Плотников и Соколовски)

и, наконец,

(vii) описание знаний, необходимых для построения математически строгой теории турбулентности (Фалькович).

Статьи этого выпуска, подготовленные на английском языке, были переведены на русский В. В. Чепыжёвым. Редколлегия журнала и организаторы конференции благодарят его за качество работы.

В связи с преждевременной кончиной В. И. Юдовича за несколько месяцев до конференции одна из секций конференции и весь этот сборник посвящаются его памяти.

K.Е. Вейн, П. Жерар, В. Крейг, С.Б. Куксин, А.Г. Сергеев, А.В. Фурсиков 